УДК 536.242; 536.4

DOI

\title{
ИННОВАЦИОННАЯ ТЕХНОЛОГИЯ И ОБОРУДОВАНИЕ ДЛЯ ПОЛУЧЕНИЯ СУППОЗИТОРИЕВ
}

\author{
Шматок А.И., к.т.н., вед. науч. сотр., Степанова О.Е., ст. науч. сотр., \\ Сильнягина Н.Б., ст. науч. сотр. \\ Институт технической теплофизики НАН Украины, г. Киев
}

\begin{abstract}
Аннотация. Предметом исследования статьи являются технология изготовления суппозиторных лекарственных форм, которые стали популярны благодаря возможности совмещения в суппозиториях ингредиентов с различными фармакологическими и физико-химическими свойствами. Предлагается использование разработанных в Институте технической теплофизики НАН Украины инновационных методов термоконтактного нагревания и плавления и дискретно-импульсного ввода энергии (ДИВЭ) для обеспечения высокого качества полученных суппозиториев. Использование метода термоконтактного нагревания $и$ плавления, который основан на непосредственном контакте нагревательного элемента с основой, позволяет сократить время на стадии подготовки основ для получения суппозиторных лекарственных форм. $A$ использование метода ДИВЭ позволяет смешивать гидрофильные и гидрофобные ингредиенты без расслоения. Проведены экспериментальные исследования метода термоконтактного нагревания и плавления для выбора оптимальных параметров проведения процесса. Изучение особенностей технологических процессов нагревания, плавления основ и диспергирования лекарственных веществ, позволило определить необходимые требования к созданию новой ускоренной технологии для изготовления суппозиториев. На базе этих исследований в ИТТФ НАНУ создано инновационное энергосберегающее оборудование для получения суппозиториев, которое соответствует правилам надлежащей практики производства.
\end{abstract}

Ключевые слова: диспергация, гомогенизация, нагревание, плавление, суппозитории.

\section{INNOVATIVE TECHNOLOGY AND EQUIPMENT FOR OBTAINING SUPPOSITORIES}

\author{
Shmatok O., PhD, Leading Researcher, Stepanova O., Senior Researcher, \\ Silnyagina N., Senior Researcher \\ Institute of Engineering Thermophysics NAS of Ukraine, Kyiv
}

\begin{abstract}
Currently, the reason for the purchase and use of imported equipment is the applying of outdated technologies and equipment for the manufacture of suppositories in Ukraine. The actual task is the hardware and technical re-equipment of existing production lines, the creation of new production facilities in the pharmaceutical industry. A method and installation of thermal contact heating and melting for the preparation of bases in the manufacture of suppositories, as a complex multicomponent dispersed system, is proposed. The experimental studies of the method of thermal contact heating and melting were carried out to select the optimal parameters for the melting process, and a graph of the melt volume dependence on the heater temperature was obtained. Intensification of the melting process is achieved by selecting the required temperature of the heater, as well as creating a uniform temperature field on the surface of the thermal contact heater due to the chosen design. The using Ti-160 thermal imager made it possible to trace the heater movement along the length of the tank, as well as the temperature distribution on the surface of the thermal contact heater and inside the metal drums of the manufacturer. The thermograms show uniform heating of the thermal contact heater and the entire volume of the melt as it moves down the drum and melts the base. Due to the low thermal conductivity coefficient, the bases are in the initial viscous state, and they heat and melt upon contact with the heater. The convective flows are observed at the end of the process, which helps to maintain the temperature of the melt at a certain level. The use of homogenizer-dispersers with the method of discrete-pulse input of energy is proposed for mixing the base with medicinal substances. The proposed technology and equipment allows to obtain the necessary consistency of suppository dosage forms, as well as to intensify the process of their manufacture and rational use of energy.
\end{abstract}

Keywords: dispersing, homogenization, heating, melting, suppositories.

Введение и формулирование проблемы. Промышленное производство суппозиториев в Украине началось с 1994 года. На фармацевтическом рынке Украины сейчас представлены суппозиторные лекарственные формы (ЛФ) примерно 50 известными фармацевтическими фирмами из 23 стран (лидеры: Германия, Франция, Италия и Швейцария) и только 5 отечественными фирмами: “Лекхим” (г. Харьков), “Монфарм” (г. Монастырище), “ФИТОЛЕК” (г. Харьков), “Сперко Украина” (г. Винница), “Фармекс Групп” (г. Борисполь) 
[1]. Устаревшие технологии и оборудование для изготовления суппозиториев предопределяет закупку и эксплуатацию импортного оборудования из Германии, Италии, США и других стран. Необходимость разработки и внедрения высокоэффективных инновационных технологий и оборудования для производства суппозиторных ЛФ обусловлена потребностью населения в отечественных фармацевтических препаратах.

Актуальной задачей является аппаратурно-техническое переоснащение действующих производств, создание новых производственных мощностей в фармацевтической отрасли в соответствии с правилами надлежащей практики производства (GMP) суппозиторных лекарственных форм.

Суппозитории - это дисперсные системы, состоящие из основы (дисперсионной фазы) и лекарственных веществ (дисперсной фазы). Они являются твердыми при комнатной температуре, а при температуре тела расплавляются для высвобождения лекарственных веществ (ЛВ). Такие системы являются сложными многокомпонентными гетерогенными системами, так как содержат одно или более лекарственных веществ, диспергированных или растворенных в простой или сложной основе.

Анализ последних исследований и публикаций. В основу технологии получения суппозиторных ЛФ (рис. 1) входит комплекс теплообменных процессов: теплопередача при нагревании, охлаждении и плавлении; перемешивание и растворение; диспергирование и гомогенизация; структурирование (получение связно-дисперсной системы).

Первой и важной стадией в технологии получения суппозиторных ЛФ является подготовка суппозиторных основ (рис. 1, стадия I). На рисунке представлено аппаратурное оформление по традиционной технологии получения суппозиториев (рис. 1, a, б, в, г, д) и аппаратурное оформление инновационной технологии, разработанной в ИТТФ НАНУ (рис. $1, \mathrm{e}$, ж, 3). Основы обеспечивают необходимую массу суппозиториев и соответственно надлежащую концентрацию лекарственных веществ, мягкую консистенцию, оказывают существенное влияние на их стабильность.

Степень высвобождения лекарственных веществ из суппозиториев, скорость и полнота их всасывания во многом зависят от природы, состава и свойств основ. Современные суппозиторные основы имеют широкий диапазон температур плавления (затвердевания), что необходимо учитывать для получения многокомпонентной основы с необходимыми структурно-механическими свойствами $[2,3]$.

Важными теплообменными процессами на стадии приготовления основ являются процессы нагревания и плавления. По традиционной технологии для нагрева и плавления основ на фармацевтических фабриках используют реакторы с различными видами мешалок (рис. 1, а), ванны с змеевиками (рис. 1, б), электротканные нагреватели, нагревательные камеры и тому подобное. Но эти методы имеют ряд существенных недостатков: трудоемкость и энергозатратность; возможен перегрев основ, что приводит к различным изменениям физико-химических и структурно-механических свойств дисперсионной фазы; контаминационно не безопасны; возможен неравномерный прогрев всей массы основы. Например, перегрев жиров и жироподобных веществ часто приводит к образованию таких форм, которые имеют более низкие температуры плавления, что влияет на качество получаемых суппозиториев. Суппозитории после перегрева основы неустойчивы при хранении, так как теряют твердость и плавятся при комнатной температуре, что также исключает возможность изготовления суппозиториев.

Материалы и методы исследований. В Институте технической теплофизики разработан метод термоконтактного плавления за счет контактного и конвективного переноса тепла, что позволяет интенсифицировать процесс и уменьшить энергозатраты. Метод плавления основы ЛФ $[4,5]$, размещенной в цилиндрической емкости, основывается на движении дискового нагревательного элемента под действием силы тяжести в процессе плавления и перетекание расплавленной основы через зазоры между диском и стенками емкости. Отличие предлагаемого метода от существующих состоит в подведении энергии непосредственно к фронту фазового превращения с помощью дискового нагревательного элемента, который контактирует с внешней границей нерасплавленного вещества.

Метод позволяет нагревать и расплавлять только ту часть основы, которая необходима, то есть реализовывать дозированный процесс плавления, что позволяет более рационально использовать энергию. При этом температуру дискового нагревателя в зоне контакта с основой поддерживают ниже температуры ее деструкции. В толще расплава поддержание температуры плавления происходит за счет конвективной теплопередачи от верхней поверхности нагревателя. 
Одеська національна академія харчових технологій ІННОВАЦІЙНІ ЕНЕРГОТЕХНОЛОГІЇ ХІМІЧНИХ І ФАРМАЦЕВТИЧНИХ ВИРОБНИЦТВ

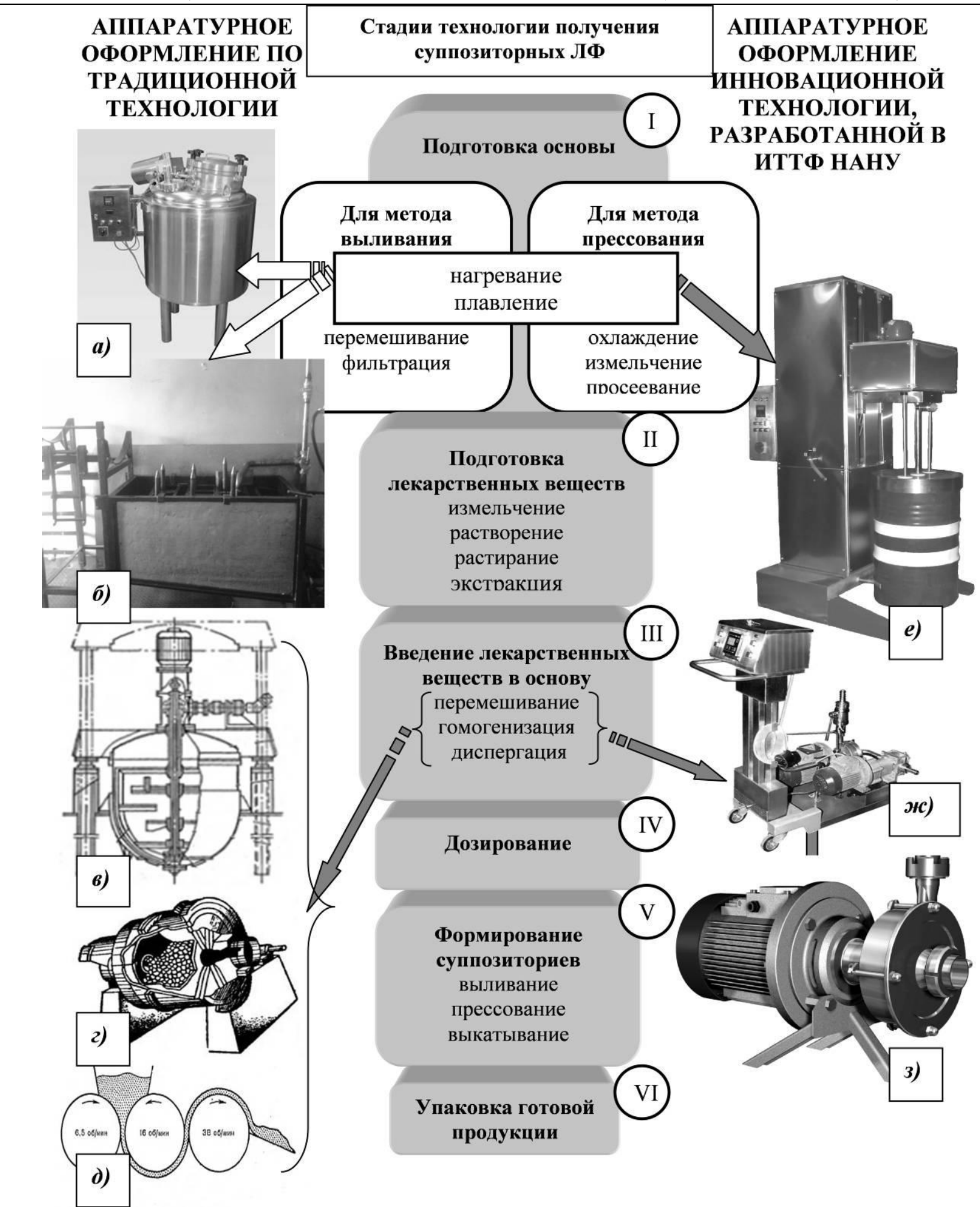

а) реактор с мешалкой; б) ванна со змеевиком; в) реактор с мешалками; г) шаровая мельница; трёхвальциовая мазетерка; е) установка “Термобат-М”; ж) мобильный агрегат “Фарматрон-3000”, з) гомогенизатор-диспергатор “АР-3000”.

Рис. 1. Блок-схема и аппаратурное оформление технологии изготовления суппозиториев.

Результаты исследований. На основе проведенных экспериментальных исследований метода термоконтактного нагрева и плавления получено график зависимости объема расплава от температуры нагревателя (рис. 2) для выбора оптимальных параметров проведения процесса плавления. Интенсификация процесса 
Одеська національна академія харчових технологій ІННОВАЦІЙНІ ЕНЕРГОТЕХНОЛОГІЇ ХІМІЧНИХ І ФАРМАЦЕВТИЧНИХ ВИРОБНИЦТВ

плавления достигается подбором необходимой температуры нагревателя, а также созданием однородного температурного поля на поверхности термоконтактного нагревателя благодаря выбранной конструкции.

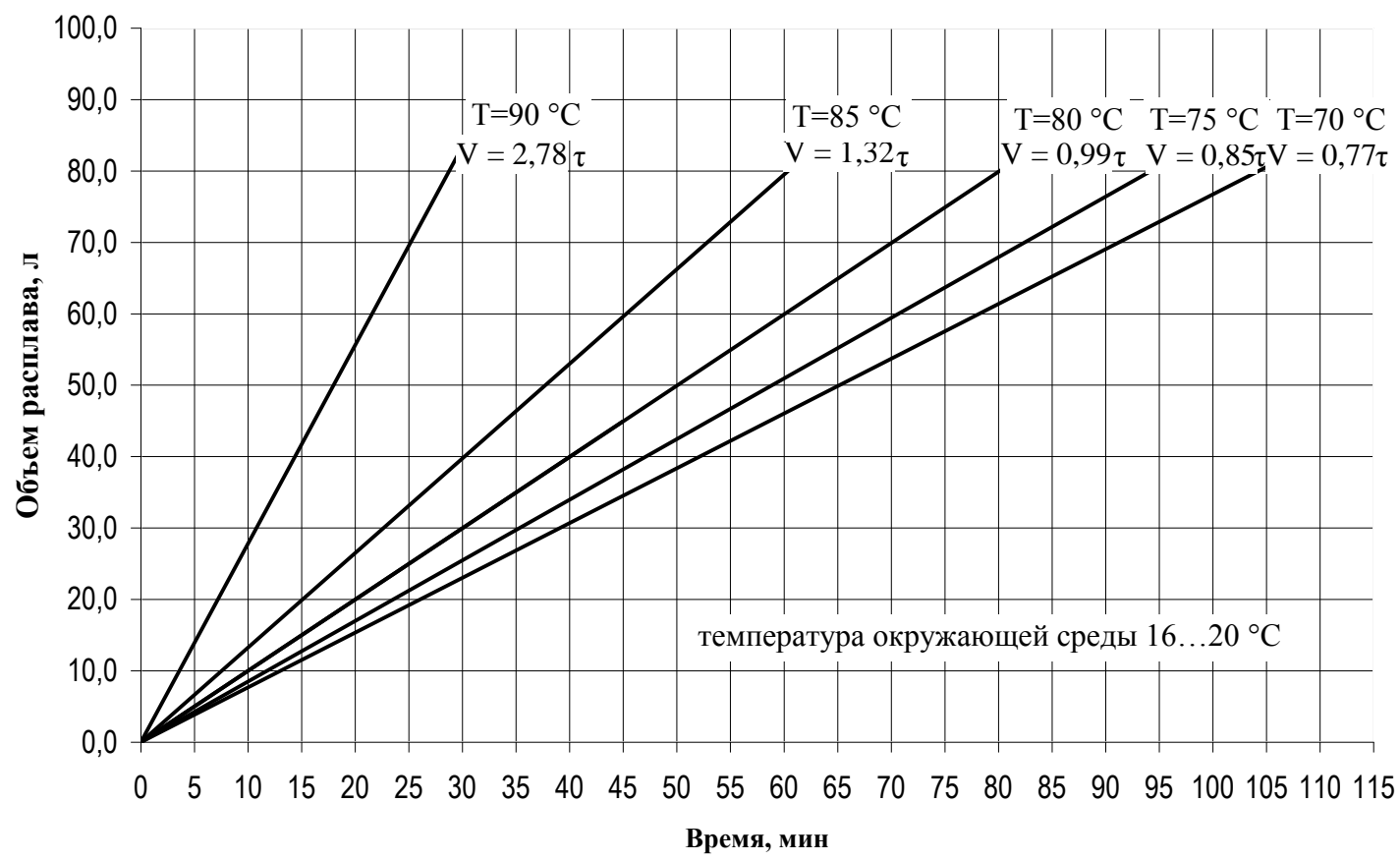

Рис. 2. График зависимости объема расплава от температуры нагревателя.

Проведенные исследования с использованием тепловизора марки Ті-160 дали возможность проследить движение нагревателя по длине емкости, а также распределение температур на поверхности термоконтактного нагревателя и внутри металлических емкостей завода-изготовителя (рис. 3). Термограммы показывают равномерный прогрев термоконтактного нагревателя (рис. 3, а) и всего объема расплава при его движении вниз емкости и плавления основы (рис. 3, б-г). Благодаря низкому коэффициенту теплопроводности, основы находятся в начальном вязком состоянии, а нагреваются и плавятся при контакте с нагревателем (рис. 3 , в). В конце процесса (рис. 3, г) наблюдаются конвективные потоки, которые способствует поддержанию температуры расплава на заданном уровне.

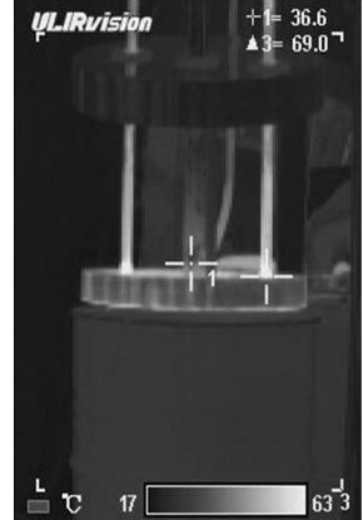

a)

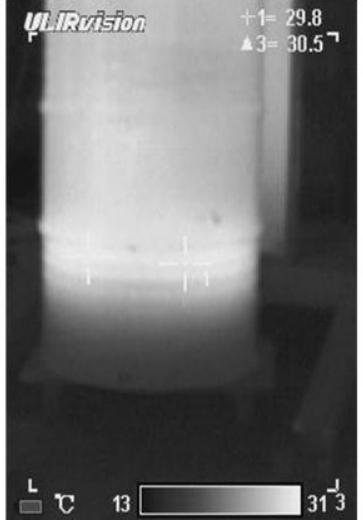

б)

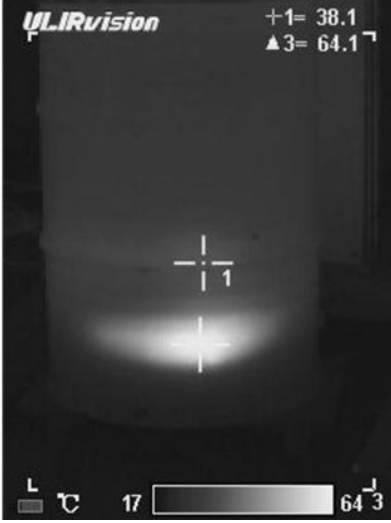

b)

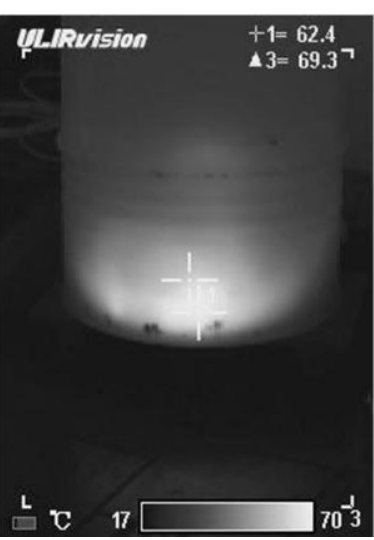

2)

а) прогрев термоконтактного нагревателя; б) начало нагрева и плавления; в) прогрев в процессе опускания термоконтактного нагревателя; г) окончания нагрева и плавления (термоконтактный нагреватель опустился на дно емкости).

Рис. 3. Термограммы процесса термоконтактного нагрева и плавления основ в емкостях заводаизготовителя.

На стадии введения лекарственных веществ в основу (рис. 1, стадия III) одной из главных задач является то, чтобы лекарственные вещества были максимально диспергированы и равномерно распределены по 
всей основе. Особенно важно это, если в составе суппозиториев присутствуют как гидрофильные, так и гидрофобные вещества.

По традиционной технологии на фармацевтических предприятиях для смешивания основы с лекарственными веществами применяют реакторы с различными мешалками. Процесс диспергирования осуществляют многоступенчато, как правило, на отдельных шаровых и молотковых мельницах со значительной потерей лекарственных веществ. Эти измельченные вещества вводят в расплав и осуществляют дальнейшую диспергацию на трехвалковых мазетерках. Как видно, эти операции осуществляют на разном оборудовании, оно периодического действия и требует тщательного выполнения правил безопасности, потому что вредит здоровью обслуживающего персонала. При применении способа диспергирования пропеллерными, шнековыми, турбинными и другими мешалками, имеют место большие затраты энергии на преодоление сил трения и вязких сил в тех зонах, где не действуют органы мешалки. Также чрезмерно тратится энергия при макроперемешивании всей массы вещества для того, чтобы обеспечить достаточную турбулизацию для получения необходимой гомогенности. В то же время, действующие методы не дают возможности смешивать гидрофильные и гидрофобные вещества без расслоения.

Многолетние исследования Институтом технической теплофизики НАНУ метода дискретноимпульсного ввода энергии позволяют исключить ряд трудоемких операций в технологии получения ЛФ и влиять на процессы перемешивания, диспергации и гомогенизации в одном аппарате, в результате чего уменьшить продолжительность этой стадии получения суппозиториев и расходы электроэнергии [6]. Разработаны и созданы гомогенизаторы-диспергаторы различных конструкций, в которых применяется метод дискретно-импульсного ввода энергии (ДИВЭ).

Гомогенизатор-диспергатор AР-3000 (рис. 1, 3) входит в созданный в ИТТФ НАНУ мобильный агрегат типа “Фарматрон-3000” (рис. 1, ж), который конструктивно выполнен с возможностью подключения к действующему на фармацевтических предприятиях технологическому оборудованию [6]. Созданный агрегат диспергирует лекарственные вещества с основой, подогревает многокомпонентный расплав и обеспечивает транспортировку и рециркуляцию расплава по технологическим трубопроводам. С помощью этого агрегата было налажено производство на ОАО “Монфарм” (г. Монастырище) стабильных суппозиториев на дифильных основах.

Созданное в ИТТФ НАНУ отечественное оборудование, соответствующее требованиям GMP, является конкурентоспособным, внедрено не только на фармацевтических предприятиях нашей страны.

\section{Выводы}

1. В Украине необходимо модернизировать действующее оборудование и разработать новое для изготовления суппозиторных форм, что обусловлено отсутствием отечественного современного энергосберегающего оборудования в фармацевтической промышленности, которое соответствовало бы международным требованиям и правилам надлежащей практики производства (GMP).

2. Опыт авторов ИТТФ НАНУ, проведенные теоретические и экспериментальные исследования позволили разработать ресурсосберегающую технологию изготовления качественных суппозиторных форм с использованием методов термоконтактного нагрева и плавления и ДИВЭ.

3. Разработанное и созданное высокоэффективное оборудование для проведения теплообменных процессов нагревания, плавления, перемешивания, диспергирования и гомогенизации при получении суппозиторных ЛФ позволяет сократить в $3 . .4$ раза удельные затраты электроэнергии, по сравнению с традиционным оборудованием.

\section{References}

1. Pertsev, I. M., Postol'nyk V. V., \& Khalyeyeva, O. L. (2001). Supozytorni likars'ki preparaty na rynku Ukrayiny. Visnyk farmatsiyi, 1(25), 43-49.

2. Lytvynenko, T. M. (2014). Suchasnyy stan asortymentu supozytornykh osnov i faktory yikh vyboru. Tekhnolohiya vyrobnytstva likiv, 1(14), 35-38.

3. Pechenezhskaya, L. A., Tikhonova, S. A., \& Piminov A.F. et al. (2006). Lekarstvennyye preparaty dlya rektal'nogo primeneniya. Ucheb. posob. M.: Izd-vo NFaU, 56.

4. Grabov, L. M., Mershchiy, V. I., \& Bondar', S. I. (2001). UA. Patent No. 31435. Kyiv: Derzhavne patentne vidomstvo Ukrayiny.

5. Grabov, L. N., Mershchiy, V. I., Vashchenko, V. N., \& Pisarenko, T. V. (2000). Optimizatsiya protsessa termokontaktnogo plavleniya materialov. Promyshlennaya teplotekhnika, 22(1), 94-99.

6. Dolinskiy, A. A., Grabov, L. N., \& Grabova T. L. (2012). Metod DPIE v innovatsionnykh tekhnologiyakh i teplomassoobmennom oborudovanii. Promyshlennaya teplotekhnika, 34(3), 18-30.

Отримано в редакцію 08.04.2019

Received 08.04.2019

Прийнято до друку 16.06.2019

Approved 16.06.2019 